\title{
Current and Potential Applications of Microalgae: A Mini Review
}

\author{
Maria N Metsoviti ${ }^{1}$, Nikolaos Katsoulas ${ }^{1}$, Ioannis T Karapanagiotidis ${ }^{2}$ and George Papapolymerou ${ }^{3 *}$ \\ ${ }^{1}$ Department of Agriculture Crop Production and Rural Environment, University of Thessaly, Greece \\ ${ }^{2}$ Department of Ichthyology and Aquatic Environment, University of Thessaly, Greece \\ ${ }^{3}$ Department of Environmental Studies, University of Thessaly, Greece
}

Submission: November 04, 2019; Published: December 05, 2019

Corresponding author: George Papapolymerou, Department of Environmental Studies, University of Thessaly, 41110, Gaioplis, Larissa, Greece

\begin{abstract}
Microalgae are unicellular photosynthetic organisms that use light and carbon dioxide, with higher photosynthetic efficiency than plants, to produce biomass. Some microalgae species can also grow and multiply heterotrophically in the absence of light if an organic carbon source becomes available. Their biodiversity is large; there are species that grow in fresh water and others in saltwater. The use of microalgae is applicable in many sectors; they are used as nutritional supplements for human nutrition, as feed ingredient in diets for animals and fish, in wastewater management, in pharmaceutical and cosmetic industry, as well as in biodiesel production.
\end{abstract}

Keywords: Microalgae; Applications; Nutritional supplements; Fish feed

\section{Introduction}

Microalgae, in general, can be used by the pharmaceutical and cosmetic industry, in wastewater management, as nutritional supplements for human nutrition and as supplement in animal and pet feeds [1,2]. As photosynthetic organisms, they contain chlorophylls that can be used for food and cosmetic purposes [3]. Some algae species contain active compounds with important pharmaceutical properties such as antibacterial and antiviral activity. Other compounds have been isolated with antitumor and anti-inflammatory activity [4,5]. Additionally, high value products can be produced by microalgae, such as carotenoids, astaxanthin, antioxidants and the long chain polyunsaturated fatty acids: docosahexaenoic acid (DHA), eicosapentaenoic acid (EPA) and arachidonic acid (AA) [6]. Another application of microalgae is found in the food industry, where they are utilised as food dyes in candies, chewing gums or beverages [7]. Over the last two decades a substantial amount of research has been conducted in order to produce biodiesel from lipids extracted from algal biomass as well as other biofuels such as ethanol.

\section{Discussion}

\section{Biodiesel Derived from Microalgae Lipids}

Biodiesel is mainly made from oils (triglycerides) derived from plants (vegetable oils) or recycled cooking oils. Lipids produced from algae have similar characteristics to vegetable oils derived from conventional plants. Cultivation of algae has many advantages over conventional plants. They can be grown on non-fertile land all year round without requirements in the use of pesticides and what is more, they have high possible photosynthetic efficiency [8]. Also, they can grow in saline water or coastal seawater. Additionally, microalgae can grow in marginal lands, such as deserts or arid lands exploiting all land surfaces [9]. Moreover, it is of great importance that production of biodiesel by microalgae results in protection from global warming and environmental pollution, by reducing the $\mathrm{CO} 2$ emissions [10]. Finally, they can grow by utilizing nutrients such as nitrogen and phosphorus from wastewaters [11] contributing to reduction of cost for nutrients for growth.

Currently, biodiesel produced from oil crops, such as palm and oilseed rape are the most widely available form of biofuels [12]. For industrial production, biodiesel must have standard quality and quantity and the production cost must be kept low, so that it can compete with conventional fuels. Microalgae can potentially be used to produce biofuels not only due to their potential of high biomass production, but also because they can produce and store significant amounts of lipids that can be converted into biodiesel $[13,14]$. Algae can be cultivated in open or closed bioreactors 
using biochemical engineering techniques and utilise CO2 either from the atmosphere or potentially from industrial exhausts. Several microalgae species are candidates and potentially can be used for biodiesel production. High lipid contents, up to $50 \%$ of the algal biomass (on a dry basis) have been achieved but biomass and subsequently lipid productivity remains low. This, as well as the high costs associated with biomass harvesting and especially lipid extraction do not allow for their commercial exploitation to produce biodiesel.

The lipid content of microalgae biomass can increase when cultivation is practised in different modes that enhance lipid accumulation (such as nutrient starvation in the culture medium). Also, genetically modified algae species are been researched in order to increase biomass and lipid productivities. At present commercial production of biodiesel from algal lipids is not competitive with fossil fuels [15]. In the future it is very doubtful that algal biodiesel will succeed commercially unless new and ingenious bioreactors will be designed, and genetically modified microalgae be developed. There is also a need for improved technologies in biomass harvesting and efficient lipid extraction. Many companies that have invested in algal biodiesel development appear to switch to new business plans concerning exploitation of algae such as the production of pigments, pet and animal feeds, specialty lipids and products for the cosmetic industry.

\section{Products of the Pharmaceutical and Cosmetic Industries}

One of the most important possible applications from microalgae is in various products of the pharmaceutical industry. The compounds that microalgae contain, have been studied for their antioxidant, antibacterial, antiviral, anti-inflammatory and anticancer properties. Microalgae produce secondary metabolites that are used for preparation of antibiotics and of various natural products [16]. According to some studies, Chlorella has anti-tumor properties [17]. Microalgae are also used in cosmetics in skin, face and hair products. Their role is to repair skin damage caused from free radicals generated from exposure to UV irradiation and accelerate skin tissue regeneration [18]. Some commercial products for skin rehydration contain polysaccharides extracted from algae. Some species used in cosmetics are: Chlorella vulgaris, Dunaliella salina, Spirulina platensis, Nannochloropsis oculata and Alaria esculenta [19].

\section{Nutritional Supplements for Human Consumption}

Microalgae can enhance the nutritional value of conventional food as they contain significant amounts of essential biochemical compounds in their biomass [3]. What is more, they are rich sources of vitamins. It is known that humans cannot synthesize all the required vitamins, and thus some vitamins have to be taken up from external sources. Therefore, microalgae in the form of capsules, powder or pills can be consumed by humans. For instance, vitamin B12 is not found in adequate amounts in conventional plants. So, people following a strict vegetarian diet need supplementation with vitamin B12 in order to avoid anemia. However, vitamin B12 is needed in the metabolism of most microalgae species and therefore it is found in adequate concentrations in their biomass. Vitamin B12 produced from marine algae has higher bioavailability compared with the commercial form of B12 produced from cyanobacteria [20].

Microalgae species are rich sources of inorganic elements which are important in human nutrition. Marine algae are a rich source of iodine, an important micronutrient necessary for the proper function of the thyroid gland. Commercially produced Spirulina biomass contains $25.5 \mathrm{mg}$ of selenium, an important micronutrient with strong antioxidant activity, as well as $1660 \mathrm{mg}$ of potassium per $100 \mathrm{~g}$ of biomass [21]. Among the advantages of use of microalgae as nutritional supplements is the fact that they do not compete with agriculture, they can be produced all year round, they demand less water than terrestrial plants for their cultivation and are free of pesticides. However, the main disadvantages are their smell and dark colour that restrict their use as nutritional supplements for human consumption. Most of nutritional supplements used for human consumption contain omega- 3 fatty acids and $\beta$-carotenes, which are derived from different microalgae species, such as Nannochloropsis sp., Phaeodactylum tricornutum, Dunaliella salina, Schizocytirum sp., Nitzschia sp., Porphyridium sp., Crypthecodinium sp., Arthrospira sp. and Isochrysis sp.

The main genuses used for supplements for human consumption are Spirulina and Chlorella. Spirulina is rich in $\gamma$ -linolenic acid that is an essential polyunsaturated fatty acid [22]. It is also rich in vitamin B1 [23] and phycobiliproteins, compounds that have high free-radical scavenging capacity, making them a potential anti-cancer and anti-tumor drug [9]. Spirulina has been characterized as a great "super-food" from the World Health Organization with high nutritional value [24] and has been added in cookies, pasta and other functional food products [25] Chlorella contains vitamins, essential amino acids, chlorophylls, minerals (sodium, potassium, iron, magnesium and calcium), $\beta$-carotene and $\beta$-1,3-glucan [26]. Other microalgae species with high nutritional value are Porphyridium cruentum, Dunaliella sp. and Haematococcus sp. Porphyridium cruentum is rich in polyunsaturated fatty acids such as arachidonic acid and EPA that are important in human nutrition [27]. Dunaliella produces carotenoids, especially $\beta$-carotene. Additionally, it produces zeaxanthin, lutein, violaxanthin, neoxanthin, cryptoxanthin and $\alpha$-carotene [28]. Haematococcus produces astaxanthin, a compound that has great antioxidant capacity; it enhances the immune system, has anti-inflammatory properties and scavenges reactive oxygen species in the digestive trat [29].

\section{Animal and Fish Feed Supplements}

The most promising microalgae feed applications, other from human consumption, are in the direction of poultry and aquaculture. Because of their high nutritional value with respect 
to protein and lipid content, their antioxidant content and their high growth rate, recently in aquaculture microalgae have received increased attention as an alternative feed source that can reduce the demand for fishmeal and fish oil. Currently, the main sources of EPA and DHA in farmed fish diets are fish oils from various fish species, mainly pelagic. However, the over-exploitation of fishery resources in combination with the growing demand for fish oil has resulted in stagnant availability and a consequent increase of its price. Moreover, the presence of chemical compounds such as PCBs \& dioxins [30] may have adverse effects on human health. For these reasons, alternative EPA and DHA sources are studied for their suitability to be used for commercial production.

Microalgae appear as a promising alternative to enhance the nutritional value of fish feeds, and to be used, at least partially, as a substitute for fishmeal and fish oil, due their high nutritional value. Depending on the species, they may contain a high percentage of proteins with a favorable amino acid profile and lipids (with significant amounts of DHA, EPA and arachidonic acid (AA) that are essential in fish diets) [31]. In addition, they have a high content of vitamins (such as A, B1, B2, B6, B12, C, E, biotin, folic acid) [32], minerals (phosphate, zinc, iron, calcium, selenium, magnesium), antioxidants, and pigments such as chlorophylls and carotenoids [33]. For instance, carotenoids from microalgae can be utilized as food additives in order to enhance the color of fish (e.g. salmons), the skin color of chickens and the yolks of eggs.

Therefore, microalgae appear to be a promising protein and lipid source for aquaculture. Specifically, some microalgae species are the initial EPA and DHA producers in the marine food chain and appear as promising alternatives of fish oil. Consequently, the use of microalgae in aquaculture could limit the environmental impact associated with intensive aquaculture, if enough quantities of biomass of microalgae could be available at suitable prices [34]. Currently, in aquaculture, microalgae are used for fish larval nutrition during a brief period either for direct consumption in the case of molluscs and penaeid shrimp or indirectly as food for the live prey fed to fish larvae. The most commonly cultured species are Nannochloropsis sp., Chaetoceros sp., Skeletonema sp., Isochrysis sp., Chlorella sp., Pavlova sp., Thalassiosira sp., Pseudoisochrysis sp., Spirulina sp., Tetraselmis sp. and Dunaliella sp. [35]. Species rich in EPA content are Phaeodactylum tricornutum and Nannochloropsis sp., while Thraustochytrium and Schizochytrium limacinum are good DHA sources [7].

\section{Other Applications}

\section{Biomethane and Biogas}

Apart from their application as biodiesel, microalgae appear as potential raw material for other applications, such as ethanol production, methane production and crude bio-oil production [35]. Methane from anaerobic digestion can be used as fuel gas and also be burned in internal combustion engines to generate electricity and thermal energy [37]. However, at present, the cost for biomethane production from algal biomass, compared with traditional sources used such as industrial and livestock waste material and crop silage, is too high [38,39]. Also, efforts for commercial production of ethanol seem to have stalled.

\section{Bioremediation of Wastewater}

Wastewater is a good source of the nutrients required for microalgae cultivation. Microalgae are effective in removing heavy metals, phosphates and nitrates found in wastewater. They can absorb nutrients since they require significant amounts of nitrogen, phosphorus and metals for their growth and production of proteins and lipids. The cultivation in wastewater can be practised with only either one species, such as various species of Chlorella, Chlamydomonas, Dunaliella, Scenedesmus and Nannochloropsis or with a mixture of different species [40]. Limited commercial applications for water decontamination are used by some companies.

\section{Conclusion}

Algae are diverse photosynthetic microorganisms which produce a plethora of valuable products. As the production cost is the predominantfactor in determining their successful exploitation it appears so far that successful applications of microalgal cultivation is limited to products that have either a relatively high value on the market or their production cost is lower compared to other sources. Such products are some pigments, vitamins, human food supplements and various products of the cosmetic industry. Other potential products such as animal feed supplements are used but limited in production output while the use of microalgae biomass as supplement in fish feed is very promising but it will depend largely if algal biomass can be produced in large scale with a cost that's competitive and if it contains appreciable amounts of EPA and DHA since, protein in fish feed is readily available from a combination of grains. Although a great deal of research has been done on biofuel production, it is still not competitive and far from being used commercially.

\section{References}

1. Slager B, Sapounas A A, Henten E J, Hemming S (2014) Modelling and evaluation of productivity and economic feasibility of a combined production of tomato and algae in Dutch greenhouses. Biosystems Engineering 122: 149-162.

2. Yeo U, Lee I, Seo I, Kim R (2018) Identification of the key structural parameters for the design of a large-scale PBR. Biosystems Engineering 171: $165-178$

3. Spolaore P, Joannis-Cassan C, Duran E, Isambert A (2006) Commercial applications of microalgae. Journal of Bioscience and Bioengineering 101(2): 87-96.

4. Sanaa M, Shanab M (2012) Aqueous extracts of microalgae exhibit antioxidant and anticancer activities. Asian Pac J Trop Biomed 2(8): 608-615.

5. Lee J C, Hou M F, Huang H W, Chang F R, Yeh CC, et al. (2013) Marine algal natural products with anti-oxidative, anti-inflammatory, and anticancer properties. Cancer Cell Int 13(1): 55. 
6. Borowitzka M A (2013) High-value products from microalgae-their development and commercialisation. Journal of Applied Phycology 25 743-756.

7. Adarme Vega T C, Lim D K Y, Timmins M, Vernen F, Li Y, et al. (2012) Microalgal biofactories: a promising approach towards sustainable omega-3 fatty acid production. Microb Cell Fact 11: 96.

8. Chisti Y, Yan J (2011) Energy from algae: Current status and future trends Algal biofuels - A status report. Applied Energy 3277-3279.

9. $\mathrm{Hu} \mathrm{Q}$ (2004) Environmental Effects on Cell Composition. In: Richmond A (Ed.) Handbook of Microalgal Culture: Biotechnology and Applied Phycology, Blackwell: Oxford, UK, Pp. 83-93.

10. Khan M I, Shin J H, Kim J D (2018) The promising future of microalgae: current status, challenges, and optimization of a sustainable and renewable industry for biofuels, feed, and other products. Microb Cell Fact 17(1): 36 .

11. Hu Q, Sommerfeld M, Jarvis E, Ghirardi M, Posewitz M, et al. (2008) Microalgal triacylglycerols as feedstocks for biofuel production: perspectives and advances. Plant J 54: 621-639.

12. Scott S A, Davey M P, Dennis J S, Horst I, Howe C J, et al. (2010) Biodiese from algae: challenges and prospects. Curr Opin Biotechnol 21: 277 286

13. Nigam P S, Singh A (2011) Production of liquid biofuels from renewable resources. Progress in Energy and Combustion Science 37(1): 52-68.

14. Chisti Y (2007) Biodiesel from microalgae. Biotechnology Advance 25(3): 294-306

15. Adesanya VO, Davey M P, Scott S A, Smith A G (2014) Kinetic modelling of growth and storage molecule production in microalgae under mixotrophic and autotrophic conditions. Bioresour Technol 157: 293 304

16. Foley P M, Beach E S, Zimmerman J B (2011) Algae as a source of renewable chemicals: opportunities and challenges. Green Chemistry 13: $1399-1405$

17. Iwamoto $H$ (2004) Industrial production of microalgal cell-mass and secondary products major industrial species Chlorella. In: Richmond A (Ed.) Handbook of microalgal culture, Oxford: Blackwell, UK, Pp. 255 263.

18. Maryam A, Salman A, Muhammad M H (2017) Algae as nutrition, medicine and cosmetic: the forgotten history, present status and future trends. World Journal of Pharmacy and Pharmaceutical Sciences 6 : 1934-1959.

19. Stolz P, Obermayer B (2005) Manufacturing microalgae for skin care. Cosmet Toilet 120: 99-106.

20. Wells M L, Potin P, Craigie J S, Raven J A, Merchant S S, et al. (2017) Algae as nutritional and functional food sources: revisiting our understanding. Journal of Applied Phycology 29(2): 949-982.

21. Guangwen T, Suter P M (2011) Vitamin A, Nutrition, and Health Values of Algae: Spirulina, Chlorella, and Dunaliella. Journal of Pharmacy and Nutrition Sciences 1: 111-118.

22. Sajilata M, Singhal R, Kamat M (2008) The carotenoid pigment zeaxanthin - A review. Comprehensive Reviews in Food Science and Food Safe 7(1): 29-49.
23. Desai K, Sivakami S (2004) Spirulina: the wonder food of the 21st century Asia. Pacific Biotech News 23: 1298-1302.

24. Khan Z, Bhadouria P, Bisen P S (2005) Nutritional and Therapeutic Potential of Spirulina. Curr Pharm Biotechnol 6: 373-379.

25. Pulz 0, Gross W (2004) Valuable products from biotechnology of microalgae. Appl Microbiol Biotechnol 65(6): 635-648.

26. Becker EW (2004) Micro algae in human and animal nutrition. In: A Richmond (Ed.) Handbook of microalgal culture, Oxford: Blackwell, UK, Pp. 312-351.

27. Arad S, Richmond A (2004) Industrial Production of Microalgal Cellmass and Secondary Products-Species of High Potential. Handbook of Microalgal Culture: Biotechnology and Applied Phycology 15: 289-566.

28. Ben Amotz A (2004) Industrial production of microalgal cell-mass and secondary products: Major industrial species: Dunaliella. In: A Richmond (Ed.) Handbook of microalgal culture, Oxford: Blackwell, Pp. 273-280.

29. Walker T, Purton S, Becker D, Collet C (2005) Microalgae as bioreactors. Plant Cell Reports 24: 629-641.

30. Hasegawa J, Guruge K S, Seike N, Shirai Y, Yamata T, et al. (2007) Determination of PCDD/Fs and dioxin-like PCBs in fish oils for feed ingredients by congener-specific chemical analysis and CALUX bioassay. Chemosphere 69: 1188-1194.

31. Brown M R, Jeffrey S W, Volkman J K, Dunstan G A (1997) Nutritional properties of microalgae for mariculture. Aquaculture, 151: 315-331.

32. Brown M R, Mular M, Miller I, Trenerry C, Farmer C (1999) The vitamin content of microalgae used in aquaculture. Journal of Applied Phycology 11: 247-255.

33. Lubián L M, Montero O, Moreno-Garrido I, Huertas I E, Sobrino C, et al. (2000) Nannochloropsis (Eustigmatophyceae) as source of commercially valuable pigments. Journal of Applied Phycology 12 (35): 249-255.

34. Shields R J, Lupatsch I (2012) Algae for aquaculture and animal feeds. Technol Assess Theory Pract 21: 23-37.

35. Patil V, Reitan K I, Knutsen G, Mortensen L M, Källqvist T, et al. (2005) Microalgae as source of polyunsaturated fatty acids for aquaculture. Plant Biology 6.

36. Gunaseelan V N (1997) Anaerobic digestion of biomass for methane production: a review. Biomass Bioenergy 13: 83-114.

37. Holm Nielsen J B, Al Seadi T, Oleskowicz-Popiel P (2009) The future of anaerobic digestion and biogas utilization. Bioresource Technology 100: 5478-5484.

38. Mata-Alvarez J, Mace S, Llabres P (2000) Anaerobic digestion of organic solid wastes. An overview of research achievements and perspectives. Bioresource Technology 74(1): 3-16.

39. Raven R P J M, Gregersen K H (2007) Biogas plants in Denmark: successes and setbacks. Renewable and Sustainable Energy Reviews 11: $116-132$.

40. Aslan S, Kapdan I K (2006) Batch kinetics of nitrogen and phosphorus removal from synthetic wastewater by algae. Ecological Engineering 28(1): 64-70. 
This work is licensed under Creative Commons Attribution 4.0 Licens

DOI: 10.19080/OFOAJ.2019.11.555811
Your next submission with Juniper Publishers will reach you the below assets

- Quality Editorial service

- Swift Peer Review

- Reprints availability

- E-prints Service

- Manuscript Podcast for convenient understanding

- Global attainment for your research

- Manuscript accessibility in different formats ( Pdf, E-pub, Full Text, Audio)

- Unceasing customer service

Track the below URL for one-step submission https://juniperpublishers.com/online-submission.php 